\title{
Mesentericin Y105 gene clusters in Leuconostoc mesenteroides Y105
}

\author{
Christophe Fremaux, ${ }^{1,2}$ Yann Héchard' and Yves Cenatiempo ${ }^{1}$
}

\begin{abstract}
Author for correspondence: Christophe Fremaux. Tel: +33494540 06. Fax: +3349453503. e-mail: Cena@Zeus.Univ-Poitiers.Fr
\end{abstract}

1 Institut de Biologie Moléculaire et d'Ingénierie Génétique, URA CNRS 1172, Université de Poitiers, 40 avenue du Recteur Pineau, 86022 Poitiers Cedex, France

2 Texel, groupe RhónePoulenc, Z. I. de Buxières, B. P. 10, 86220 DangéSaint-Romain, France

\begin{abstract}
Because of their potential usefulness as natural food preservatives, increased interest has focused on bacteriocins from lactic acid bacteria. Mesentericin Y105 is a small non-lantibiotic bacteriocin (class II) encoded within a 35 kb plasmid from Leuconostoc mesenteroides Y105 and it is active against Listeria monocytogenes. Using reverse genetic methodologies, an $8 \mathrm{~kb}$ Drall fragment has been cloned that contains the mesentericin Y105 structural gene, mesY, which encodes a precursor of the bacteriocin with a 24 amino acid $\mathbf{N}$-terminal extension ending with a Gly-Gly motif upstream of the cleavage site, which is typical of class II bacteriocins. Four other putative genes are associated with mesY within two divergent putative operons. In addition to mesY, the first putative operon is predicted to encode a protein, similar to that encoded by ORF2 in the leucocin A operon, whose function remains to be elucidated. The second putative operon contains three ORFs, two of which, mesD and mesE, encode proteins that resemble ATP-dependent transporters and accessory factors, respectively. For three other class II bacteriocin systems (lactococcin A, pediocin PA-1, colicin V), these proteins have been shown to be involved in bacteriocin secretion independently of the general sec-dependent secretion pathway. The last putative gene (mesC) does not resemble any previously characterized gene. Results concerning the heterologous expression of the cloned mesY in Lactobacillus johnsonii NCK64 suggest that the maturation and secretion functions dedicated to lactacin F (another class II bacteriocin) are efficient for mesentericin Y105 as well. This characteristic may be of great interest in the development of industrial fermentation starters producing multiple bactericidal activities.
\end{abstract}

Keywords: bacteriocin, mesentericin Y105, lactic acid bacteria, ABC transporter, Listeria

\section{INTRODUCTION}

Because of the trend to reduce the use of chemical additives in food protection against pathogens and other undesirable organisms, increased interest has been focused on bactericidal compounds produced naturally by organisms that are 'generally recognized as safe'. Antimicrobial activities of lactic acid bacteria have been widely investigated over the past decade (De Vuyst \& Vandamme, 1994). Among such natural inhibitors, proteinaceous compounds, called bacteriocins, inhibit closely related species (Tagg et al., 1976) and, therefore, appear to be good candidates for use as biological food preservatives.

The GenBank/EMBL/DDBJ accession number for the sequence reported in this paper is $X 81803$.
The lactic acid bacterium Leuconostoc mesenteroides Y105 isolated from goat's milk produces a bacteriocin (mesentericin Y105) that is bactericidal against Listeria species (Héchard et al., 1992a, b). This peculiar characteristic may be of great interest in the development of strains that are active against pathogens without affecting the natural microflora of dairy products and other fermented foods. Mesentericin Y105 is a small heat-stable peptide, devoid of lanthionine residues, and contains the N-terminal YGNGVXC consensus motif (Héchard $e t$ al., 1992a) commonly found in all anti-Listeria bacteriocins and typical of the pediocin-like bacteriocins, as defined by Nieto Lozano et al. (1992). Therefore, it can be classified as a class IIa bacteriocin, according to the classification of Klaenhammer (1993). Mesentericin Y105 as well as other class II bacteriocins provoke a depolarization of the cytoplasmic membrane of sensitive bacteria (van Belkum 
et al., 1991b; Chikindas et al., 1993; Maftah et al., 1993; Venema et al., 1993; Abee et al., 1994).

Over the past five years, there has been a burst of research activity at the molecular level on the class II bacteriocins produced by lactic acid bacteria. To date, the primary structures for a few of these bacteriocins have been elucidated and their structural genes characterized. These include lactacin $\mathrm{F}$ from Lactobacillus jobnsonii (Muriana \& Klaenhammer, 1991; Fremaux et al., 1993; Allison et al., 1994), lactococcin A, B and M from Lactococcus lactis subsp. cremoris (van Belkum et al., 1991 a, 1992; Holo et al., 1991), leucocin A from Ln. gelidum (Hasting et al., 1991), pediocin PA-1 from Pediococcus acidilactici (Marugg et al., 1992), sakacin A from Lb. sake (Holk et al., 1992), and carnobacteriocin A from Carnobacterium piscicola (Worobo et al., 1994). Colicin V is another bacteriocin that can be classified within class II, even though it is produced by Escherichia coli, a Gram-negative organism (for a review see Fath et al., 1992). Colicin V export is independent of the general secretion pathway and involves two genes genetically linked and associated with the bacteriocin structural gene. These two genes, encoding an ATPdependent transporter and an accessory factor, have been well characterized for colicin $\mathrm{V}$ export. Of the class II bacteriocins from lactic acid bacteria, $A B C$ transporter genes have only been cloned for lactococcins and pediocin PA-1 (Marugg et al., 1992; Stoddard et al., 1992). However, there is no biological evidence for their effective involvement in bacteriocin export.

In this study, the mesentericin Y105 structural gene $(m e s Y)$ has been cloned from Ln. mesenteroides plasmid pHY30 using reverse genetics, and transferred to a strain of Lb. jobnsonii. Heterologous expression was obtained and the bacteriocin was efficiently produced. The nucleotide sequence of mes $Y$ and its flanking regions have been determined. It appears to be encoded within an operon together with another ORF that encodes the putative immunity peptide against mesentericin Y105. A second operon, divergent from the mes $Y$ operon, encodes three proteins. Two of them, MesD and MesE, resemble the $\mathrm{ABC}$ transporters and their accessory factors, respectively. The third protein encoded within the operon does not display any similarity with proteins from databases.

\section{METHODS}

Bacterial strains, cultures and plasmids. Bacterial strains and plasmids used in this study are detailed in Table 1. E. coli strains were propagated at $37^{\circ} \mathrm{C}$ in LB broth or on agar $(1.5 \%$, w/v) (Sambrook et al., 1989). Ampicillin, erythromycin, IPTG and $\mathrm{X}-\mathrm{Gal}$ were used at concentrations of $75,150,50$ and $50 \mu \mathrm{g} \mathrm{ml}^{-1}$, respectively. Erythromycin-resistant transformants of E. coli were selected on brain heart infusion agar plates (Difco). Lactic acid bacteria were propagated in MRS (Difco) broth or on agar $(1.2 \%, \mathrm{w} / \mathrm{v})$ at $30^{\circ} \mathrm{C}$ for Ln. mesenteroides strains and at $37^{\circ} \mathrm{C}$ for Lb. johnsonii. When appropriate, erythromycin was added to $3 \mu \mathrm{g} \mathrm{ml}^{-1}$. L. monocytogenes $\mathrm{E} 20$ was grown at $30^{\circ} \mathrm{C}$ in trypic soy broth (Difco). To obtain plasmid-cured derivatives of $L n$. mesenteroides Y105, cultures were performed in MRS broth containing a sublethal concentration of novobiocin $\left(5 \mu \mathrm{g} \mathrm{ml}^{-1}\right)$.
After about 15 generations, colonies were isolated, assayed for bactericidal activity and their plasmid content was analysed as described below.

Bacteriocin assays. The critical dilution assay (Mayr-Harting $\mathrm{et}$ al., 1972; Barefoot \& Klaenhammer, 1983) was used for bacteriocin titration. Mesentericin Y105 was assayed in MRS broth cultures that were propagated overnight. Twofold serial dilutions of cell-free supernatant were spotted on MRS agar and then overlaid with $5 \mathrm{ml}$ tryptic soy agar $(0.6 \%, \mathrm{w} / \mathrm{v})$ inoculated to $1 \%$ with the indicator strain. After overnight incubation at $30^{\circ} \mathrm{C}$, bacteriocin titres were determined and expressed in activity units per $\mathrm{ml}\left(\mathrm{AU} \mathrm{ml} \mathrm{m}^{-1}\right)$.

DNA manipulation, cloning and transformation. Plasmids from E. coli and lactic acid bacteria were extracted and purified as previously described by Sambrook et al. (1989) and Muriana \& Klaenhammer (1987), respectively. Plasmid DNA was digested with restriction enzymes (Gibco-BRL) according to the supplier's recommendations. Analytical and preparative agarose gel electrophoresis in Tris-borate/EDTA ( $\mathrm{pH} 8.3$ ) was done according to the methods of Sambrook et al. (1989). DNA restriction fragments were purified from agarose gels using the Prep-a-Gene kit (Bio-Rad). Recombinant DNA was obtained using the T4 DNA ligase (Gibco-BRL) following the manufacturer's recommendations. E. coli competent cells were prepared and transformed according to the methods of Hanahan (1983). Lactic acid bacteria were transformed by electroporation in $0.2 \mathrm{~cm}$ cuvettes in a Gene Pulser apparatus (Bio-Rad; settings $25 \mu \mathrm{F}, 2.5 \mathrm{kV}, 200 \Omega$ ). Electro-competent cells were prepared according to the method of Raya et al. (1992).

Hybridization. Plasmids and DNA fragments cleaved with the appropriate restriction enzyme were transferred from agarose gels to nylon membranes (Hybond-N + ; Amersham) as described by Southern (1975), then treated according to the supplier's instructions. Probes were labelled by random priming as described by Sambrook et al. (1989).

PCR. mes $Y$ gene amplification by PCR was done using primers YN1, 5'-GGATCCAAGTATTATGGTAACGGAGTTCATTGCACA, and YN2, 5'-ATGAATTCCCAGAAACCATTTCCACCAT, deduced from the mesentericin Y105 amino acid sequence (Héchard et al., 1992a). Amplifications were carried out with Taq DNA polymerase (Perkin Elmer Cetus) according to the supplier's recommendations using the Gene Ataq thermocycler (Pharmacia) under the following conditions: $30 \times$ (denaturation, $94^{\circ} \mathrm{C}$ for $30 \mathrm{~s}$; annealing, $53{ }^{\circ} \mathrm{C}$ for $30 \mathrm{~s}$; elongation, $72^{\circ} \mathrm{C}$ for $1 \mathrm{~min}$ ).

DNA sequencing and computer analysis. Part of the $8 \mathrm{~kb}$ DraII (5235 bp) insert from pCFYC2 $(+)$ and $-(-)$ has been sequenced. The insert was first subcloned in parts (see below, Fig. 2, pCFYC3 and pCFYC4), then random nested deletions were created using the Erase-a-Base system (Promega) to generate plasmid for sequencing. Sequencing, based on the chain-termination method (Sanger et al., 1977), was done with the Auto-read sequencing kit (Pharmacia) using either standard or specific primers with an automated DNA sequencer (ALF, Pharmacia). Sequence analysis was performed with the programs of the GCG sequence analysis software package.

\section{RESULTS}

\section{Location of the mesY}

To obtain a DNA probe specific to mes $Y$, two oligonucleotide primers (YN1 and YN2) deduced from the amino acid sequence of the secreted mesentericin Y105 (MesY) were synthesized. YN1 fits the N-terminus of the 
Table 1. Bacterial strains and plasmids

\begin{tabular}{|c|c|c|}
\hline Strain/plasmid & Relevant characteristics & Reference/source \\
\hline \multicolumn{3}{|l|}{ Strain } \\
\hline \multicolumn{3}{|l|}{ E. coli } \\
\hline DH5 $\alpha$ & 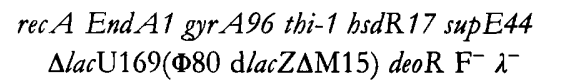 & BRL \\
\hline CFYC2 & $\mathrm{DH} 5 \alpha\left(\mathrm{pCFYC} 2+/-^{*}\right)$ & This study \\
\hline CFYC3 & DH5 $\alpha($ pCFYC3) & This study \\
\hline CFYC4 & $\mathrm{DH} 5 \alpha(\mathrm{pCFYC4})$ & This study \\
\hline CFYC5 & $\mathrm{DH} 5 \alpha(\mathrm{pCFYC5})$ & This study \\
\hline \multicolumn{3}{|l|}{ Ln. mesenteroides } \\
\hline Y105 & $\mathrm{MesY}^{+}, \mathrm{pHY} 30, \mathrm{pHY} 15, \mathrm{pHY} 3, \mathrm{pHY} 2$ & Héchard et al. (1992) \\
\hline $\mathrm{Y} 30$ & $\mathrm{MesY}^{-}, \mathrm{pHY} 15, \mathrm{pHY} 3, \mathrm{pHY} 2$ & This study \\
\hline Y31 & MesY $^{-}, \mathrm{pHY} 15, \mathrm{pHY} 3, \mathrm{pHY} 2$ & This study \\
\hline $\mathrm{Y} 32$ & $\mathrm{MesY}^{-}$, pHY15, pHY3, pHY2 & This study \\
\hline \multicolumn{3}{|l|}{ Lb. johnsonii } \\
\hline NCK64 & NCK88 derivative, laf $A 729, \mathrm{Laf}^{-}, \mathrm{Mes}^{\mathbf{R}}$ & Allison et al. (1994) \\
\hline NCK 65 & NCK88 derivative, $\Delta$ laf, Laf $^{-}, \mathrm{MesY}^{\mathbf{R}}$ & Allison et al. (1994) \\
\hline CFYC6 & NCK64(pGKV210) & This study \\
\hline CFYC7 & NCK65(pGKV210) & This study \\
\hline CFYC8 & NCK64(pCFYC5), MesY ${ }^{+}$ & This study \\
\hline CFTC9 & NCK65(pCFYC5), MesY ${ }^{+}$ & This study \\
\hline \multicolumn{3}{|l|}{ L. monocytogenes } \\
\hline $\mathrm{E} 20$ & Mes $Y$-sensitive indicator & $\begin{array}{l}\text { IUT la Rochelle; } \\
\text { Héchard et al. (1992) }\end{array}$ \\
\hline \multicolumn{3}{|l|}{ Plasmid } \\
\hline pBluescript II SK + & $A m p^{\mathrm{R}}$, lac $Z$, cloning vector, $2.9 \mathrm{~kb}$ & Stratagene \\
\hline pUC18 & $A m p^{R}$, lac $Z$, cloning vector, $2.9 \mathrm{~kb}$ & Pharmacia \\
\hline pGKV210 & $\begin{array}{l}\text { Erm }^{\mathrm{R}} \text {, E. coli-lactic acid bacteria shuttle } \\
\text { vector, } 4 \cdot 4 \mathrm{~kb}\end{array}$ & $\begin{array}{l}\text { van der Vossen } \text { et al. } \\
(1987)\end{array}$ \\
\hline pYHYC1 & $\begin{array}{l}\text { pUC18:: } 127 \text { bp EcoRI-BamHI PCR } \\
\text { fragment }\end{array}$ & This study \\
\hline pCFYC2 $+/-^{*}$ & $\begin{array}{l}\text { pBluescript II SK }(+):: 8 \cdot 0 \mathrm{~kb} \text { DraII } \\
\text { fragment from } \mathrm{pHY} 30\end{array}$ & This study \\
\hline pCFYC3 & $\begin{array}{l}\text { pBluescript II SK(+)::4.0 kb SacI-DraII } \\
\text { fragment from } \mathrm{pHY} 30\end{array}$ & This study \\
\hline pCFYC4 & $\begin{array}{l}\text { pBluescript II SK }(+):: 4 \cdot 0 \mathrm{~kb} \text { DraII-SacI } \\
\text { fragment from } \mathrm{pHY} 30\end{array}$ & This study \\
\hline pCFYC5 & $\begin{array}{l}\text { pGKV210::1.7 kb NsiI-PstI fragment from } \\
\text { pHY30 }\end{array}$ & This study \\
\hline
\end{tabular}

$*+/-$ Depending on the insert orientation.

mature MesY with a $\mathrm{Bam} \mathrm{HI}$ restriction site $5^{\prime}$-extension, and $\mathrm{YN} 2$ fits the C-terminus of MesY with an EcoRI restriction site 5 '-extension. Using these primers, PCR amplification of a plasmid DNA preparation from $L n$. mesenteroides Y105 generated a unique DNA fragment of $127 \mathrm{bp}$. This fragment was cloned within the Bam HI and EcoRI sites of pUC19, generating pYHYC1, and its sequence was determined. The DNA sequence of the cloned fragment encoded a deduced peptide that is identical to the mature MesY.

The BamHI-EcoRI insert from pYHYC1 was purified from an agarose gel and used as a probe in Southern blot hybridization with plasmid DNA extracted from $L n$. mesenteroides Y105. The strain contains four plasmids, pHY30, pHY15, pHY3 and pHY2, of about 35, 15, 3.5 and $2.5 \mathrm{~kb}$, respectively (Fig. 1a); the probe hybridized to pHY30 (Fig. 1b). Similar analysis with total DNA extracted from Ln. mesenteroides Y105 displayed no hybridization to chromosomal DNA (not shown). These data located mes $Y$ within pHY30. In addition, Ln. mesenteroides Y105 derivatives ( $\mathrm{Ln}$. mesenteroides Y30, Y31 and Y32) that did not produce the bacteriocin were obtained by novobiocin treatment $\left(0.5 \mu \mathrm{g} \mathrm{ml}^{-1}\right)$. Plasmid profiling revealed the absence of $\mathrm{pHY} 30$ from these strains (Fig. 1a), thus providing correlative evidence for the involve- 


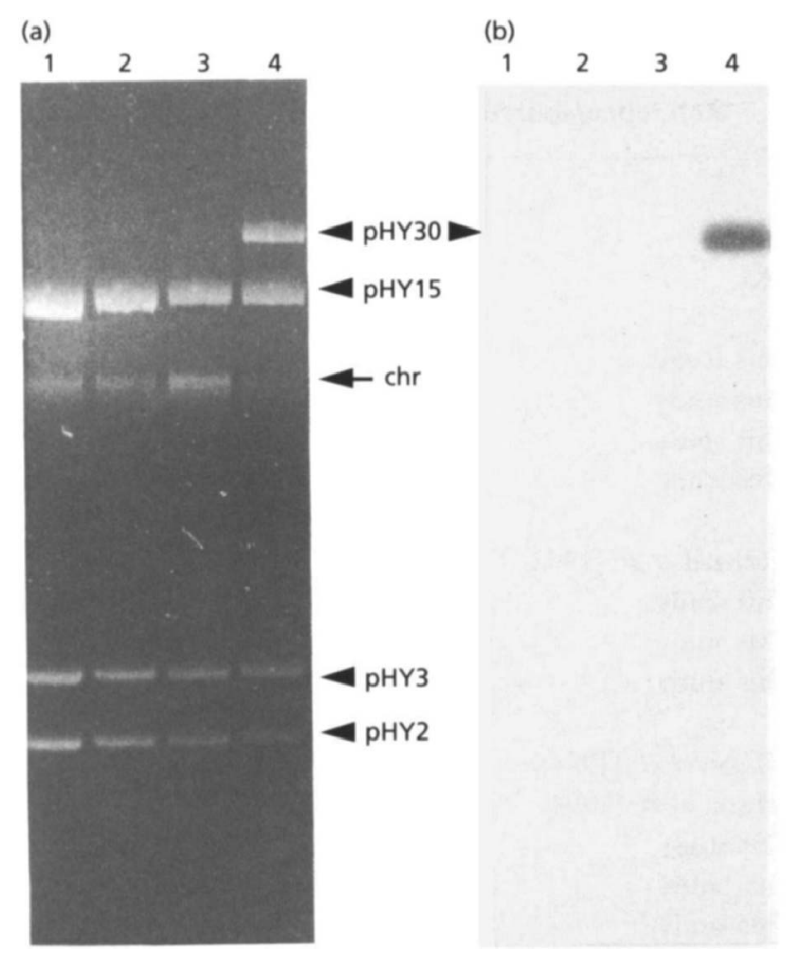

Fig. 1. Agarose gel electrophoresis (a) and Southern blot hybridization (b) of plasmid extracts with a mesY-specific DNA probe isolated from pYHYC1. Plasmids were extracted from $L n$. mesenteroides Y32 (lane 1), Y31 (lane 2), Y30 (lane 3), Y105 (lane 4). Arrowheads indicate the plasmids and their size has been estimated (see text) by comparison with a supercoiled DNA standard ladder (GIBCO-BRL). Traces of chromosomal DNA (chr) are arrowed.

ment of pHY30 in bacteriocin production. A partial restriction map of a $20 \mathrm{~kb}$ fragment from $\mathrm{pHY} 30$ which contains mes $Y$ was prepared and is shown in Fig. 2.

\section{DNA sequencing of the mes $Y$ region}

An $8 \mathrm{~kb}$ Drall fragment, purified from $\mathrm{pHY} 30$, which hybridized to the $127 \mathrm{bp} B a m \mathrm{HI}-E c o \mathrm{RI} m e s Y$-specific sequence in PYHYC1 was cloned within the DraII restriction site of pBluescript II SK( +$)$, generating pCFYC2 $(+)$ and $-(-)$, depending on the insert orientation (Fig. 2). Plasmids pCFYC3 and pCFYC4 were generated from $\mathrm{pCFYC} 2(+)$ and $-(-)$ by deletion of a $4 \mathrm{~kb}$ fragment using $\mathrm{Sac}$ I restriction sites (one internal to the DraII insert and the other located within the multicloning site). Using these plasmids and deleted derivatives, and specific synthetic primers, 5235 bp out of the $8 \mathrm{~kb}$ Drall fragment have been sequenced (Fig. 3). Computer analysis of the sequence, in all possible reading frames, identified two ORFs named mesI and mes $Y$ on one strand, and three ORFs on the other strand, named mes $C$, mes $D$ and mesE, thus defining two gene clusters. Each ORF, except mes $D$, is preceded by a putative ribosomebinding site. Within the first gene cluster, mes $Y$ encoded a protein which consists of 61 amino acid residues. Amino acid residues 25 to 60 , predicted from mes $Y$ (Héchard $e t$ al., 1992), correspond entirely to the amino acid sequence determined for mesentericin Y105. This indicates that the mes $Y$ gene encodes a precursor of the bacteriocin with a 24 amino acid $\mathrm{N}$-terminal extension, which is probably cleaved during secretion. Positioned 20 bp downstream of mes $Y$, mesI is likely to start with the less frequently used TTG initiation codon, and encodes a putative protein of 113 amino acids. In E. coli, TTG replaces the ATG initiation codon in some genes (Kozak, 1983), whereas in Leuconostoc sp. this phenomenon has been described only once (Hastings et al., 1991). Just downstream of mesI, computer analysis predicted a stem-loop structure (the stem and the loop are 27 and $9 \mathrm{bp}$ long, respectively) that might act as a terminator (calculated free energy of formation, $\Delta G_{0},-42.2 \mathrm{kcal} \mathrm{mol}^{-1} ;-176.6 \mathrm{~kJ} \mathrm{~mol}^{-1}$ ). The second group of putative genes starts with mes $C$ which encodes a 137 amino acid protein. It is followed at 46 bp by two ORFs separated by 9 residues, mesD then mesE, that encode two large proteins of 722 and 457 amino acid residues, respectively.

These two clusters of putative genes are transcribed in opposite directions, and are separated by a $154 \mathrm{bp}$ noncoding region that should contain both promoter regions (Figs 2 and 3). Within this area, three putative promoters P1, P2 and P3, as described in Fig. 3, present strong identities with characterized constitutive promoters driving the transcription of several genes in lactic acid bacteria (van der Vossen et al., 1987; Koivula et al., 1991). This organization suggests that these five ORFs may be transcribed as two operons. Indeed, messenger RNA analyses need to be performed to confirm this hypothesis. A schematic representation of the mesentericin Y105 region organization is displayed in Fig. 2.

\section{Heterologous expression of the mesentericin Y105}

A $1.7 \mathrm{~kb}$ PstI-NsiI fragment from pCFYC3 (Fig. 2) was isolated and inserted within the unique $P s t \mathrm{I}$ restriction site of pGKV210, an E. coli-lactic acid bacteria shuttle vector encoding erythromycin resistance and a promoterless cat (van der Vossen et al., 1987). The resulting construction (pCFYC5; Fig. 2), contains mes $Y$, mesI, and their upstream region, including their putative promoter and mes $C$ with a truncated C-terminus. No erythromycin-resistant $\left(\mathrm{Erm}^{\mathrm{R}}\right)$ transformants were obtained with $L n$. mesenteroides Y105 and Y30.

Consequently, Lb. jobnsonii NCK64 and NCK65, derived from the lactacin F-producing strain Lb. jobnsonii NCK88 (Muriana \& Klaenhammer, 1987), were investigated for their ability to express mesentericin Y105. Both are lactacin $\mathrm{F}$ non-producing strains and are insensitive to mesentericin Y105. NCK64 has a frameshift mutation within the lactacin F structural gene and NCK65 has a chromosomal deletion of about $10 \mathrm{~kb}$ affecting the lactacin F operon (Allison et al., 1994). Good transformation efficiencies were obtained using pGKV210 and erythromycin selection; however, the efficiency decreased by two orders of magnitude when pCFYC5 was used for the transformations. Moreover, the resulting transformants had poor growth rates and decreased plasmid copy numbers. Their ability to produce mesentericin Y105 


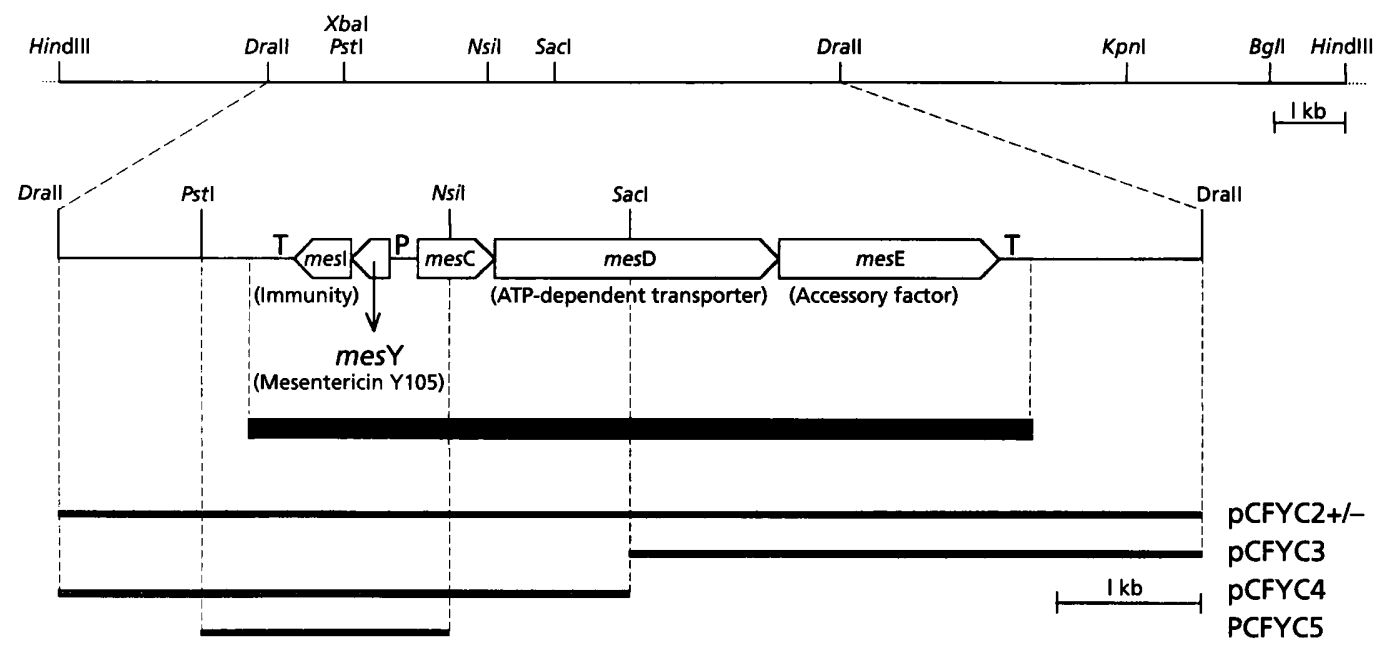

Fig. 2. Schematic overview of the genetic organization of the mesentericin Y105 gene clusters. The upper part of the diagram displays a partial restriction map of the $20 \mathrm{~kb}$ Hindlll fragment from pHY30. The restriction fragments cloned within plasmids pBluescript II SKi +) (for pCFYC2, pCFYC3 and pCFYC4) and pGKV210 (for pCFYC5) are indicated by shaded bars in the bottom part of the figure. The diagram locates the ORFs and their respective orientation (arrowed boxes). The putative function of the proteins deduced from ORFs is indicated. $\mathrm{P}$ and $\mathrm{T}$ indicate putative promoter and terminator regions, respectively. The solid bar represents the portion of the insert whose sequence has been determined on both strands.

was analysed (Table 2). NCK64(pGKV210) and NCK65(pGKV210) were not bactericidal against $L$. monocytogenes E20. NCK64 and NCK65 transformed with pCFYC5 stably produced variable amounts of mesentericin Y105 ranging from 100 to $3200 \mathrm{AU} \mathrm{ml}^{-1}$. To analyse the efficency of the putative promoter located downstream of mesI, chloramphenicol MICs were determined for CFYC8 and -9 and compared to those of CFYC6 and -7 (containing pGKV210). No difference was observed between these strains. Thus, because of the absence of obvious coding sequences downstream of mesI (sequence not shown), the inverted repeats located behind mesI are likely to act as a transcriptional terminator.

\section{Similarity of the mesentericin Y105 to the leucocin A- UAL 187}

Hastings et al. (1991) purified leucocin A, an anti-Listeria bacteriocin from Leuconostoc gelidum UAL 187. In addition, they analysed a 1088 bp plasmid-derived fragment from Ln. gelidum UAL 187 that contains the precursor leucocin A gene (ORF1), the putative immunity gene (ORF2), and their upstream and downstream sequences. Héchard $e t$ al. (1992a) pointed out some striking identities between this bacteriocin and the purified mesentericin Y105. Differences involved replacements of residues 22 and 26 of the mature peptide and an additional tryptophan at the $\mathrm{C}$-terminus of the leucocin A. Analysis of the peptide sequence deduced from mes $Y$ confirmed the differences in position 22 and 26. However, similarly to leucocin A, MesY ended with a tryptophan residue. Analysis of the native MesY and leucocin A, deduced from their gene sequence, displayed a less conserved $\mathrm{N}$-terminal extension (7 differences over 24 amino acids, data not shown).
Amino acid sequence alignment showed important similarities $(74.5 \%$ identity, mostly located within the Cterminus) between the protein deduced from mesI (MesI) and the putative leucocin A immunity protein (deduced from ORF2, data not shown). However, no sequence similarity between mesI and ORF2 was found downstream. In addition, upstream of the leucocin A structural gene a truncated ORF has been found that is $72 \%$ identical to the $\mathrm{N}$-terminus of $\mathrm{MesC}$, and the resulting intergenic region is $77 \%$ identical to the promoter region between mes $Y$ and mesC (data not shown).

\section{Similarity of the mesC-mesD-mesE gene cluster to ATP-dependent transport systems}

Searches for protein homologies revealed that the proteins deduced from mesD (MesD) and mesE (MesE) share significant similarity with proteins known as $A B C$ transporters and accessory factors, respectively. $A B C$ transporters and accessory factors are two proteins that form secretion systems independent from the signal peptidedependent export pathway in various prokaryotic organisms (Fath \& Kolter, 1993). The predicted MesD consists of a large, mostly hydrophobic, $\mathrm{N}$-terminus (with seven potential membrane-spanning segments), and a C-terminus containing the conserved 200 amino acid domain unique to ATP-dependent transporters (Fig. 3) (Fath \& Kolter, 1993). The best similarity score was obtained with LcnC ( $75.8 \%$ similarity), the putative ATP-dependent transporter dedicated to lactococcins A, B and M (Stoddard et al., 1992; van Belkum, 1994). Similarly, MesD is homologous to ComA (75\%) and PedD (66.2\%), the putative ATP-dependent transporters for the competence factor of Streptococcus pneumoniae (Hui \& Morrison, 1991) and the pediocin PA-1 (Marugg et al., 
AAAATGTCCAATAATTAACCTAATACCTGTCAACATTCAAAGTAAATATATCCAAAATCC AGTTAACAGTAACTAATATTGATTTATCTATTCGAAATTCATCATGTAGTTTCATCCATA TTTTCCCCTAGAGTTTAATCATATTTAAAAGCCTTGTACAATTGAAAAATTAAATTGTAC AAGGCTTTTAAATATGATTTACTGATCGAAAACGCTGTAAAACTGAGACTTGTCTGAAAA
$-Q \quad \mathrm{D}$ ATCAGCCATATACTGACCATTAAGTCCAGCTTTTTGTCCAATAACACCAAGTTTTATAAT CAATTCCTCTTCTTTTTTTGAAAAAATAATTTTGTATGTTGAaGCAGTAATACGAATATA

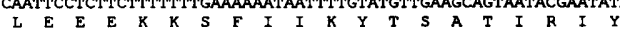
ATTAACCAATCGATTAATTAGCGCTTCAACACTTTGAGTATTATCCAACTTCTTAGAAAC

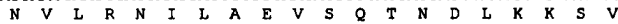

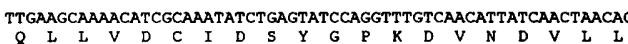

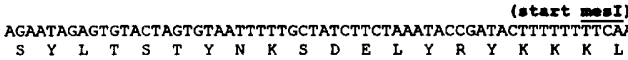

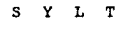

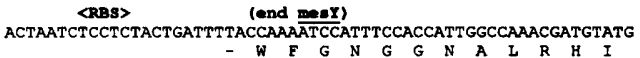
(ends) manY)
ACTAATCTCCTCTACTGATTTTACCAAA
- ATCCATTTCCACCATTGGCCAAACGATGTATG CCAGCTGAGGCAGCTTCTCCCCAGTTAACAGAGCATCCACTTTTTGTACAGTGAACACCA TTCCCATAATACTTTCCACCAACAACTTTCTTGAGATTCTGGTTATCTAATTGCTGATAT

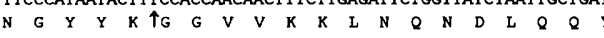

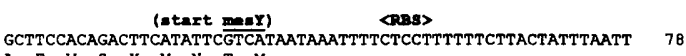

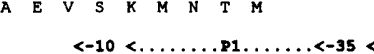
CACATTGATTATATATCTAAATTATTTTTAAATCAATATTTCTTGTTATATAAATATTT $>-35>\ldots \ldots .72 \ldots \ldots,>-10>\quad>-35>\ldots \ldots . .13 .$. <RBS> TTTTATTTTTATGTTAGAATAATGAGTGTTATGTGTTTCACTTTTTAATGGAGATAAGGT 900 1..>-10>

(etart mac)

ATGCCTGATTTAAACATAAATGAAGATTTGATTAATAACTACCAAAAACTAACGAATGAT 960 ATAGAAATATTTCACGAAATATCCTACATCGATTTTTATAATAAAATGAATAATGGAAAA 1020 $\begin{array}{llllllllllllllllllllll}I & E & I & F & H & E & I & S & Y & I & D & F & Y & N & K & M & N & N & G & K & 40\end{array}$ AATAGTTTAATTTACCTTGGTAAACCAACGTGTCCTATTTGTGTCAAATTTGTGCCTATG 1080

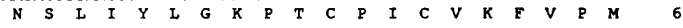
CTGCATGACATTTTGGCTGCTAAAAATATGCATATTGATTACTTTAATGTGGATACTTTT 1140

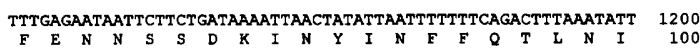
TCCCAACTTCCATCTTTGATTTTTACTCATGGAGATATGAACTATCAACGTTTACCCATT 1260 TATACAATAAAAACACCAATAAATGCCTGGATTACAGCAATTAACGĀAAA)

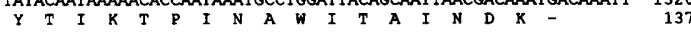
(atart map) TATGTCAAAAACTCCTAAACAATCATCAACGAATTAAAAAATGGTTAAAACTCCAATGTT 1380 TCATAAAAAAATAGATTATATTTCACAAGTAGATGAACGTGATTGTGGTGTGGCTGCACT 1440

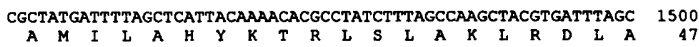
CAAAACGGATATGGAAGGACGACTGCTTTAGGCATTGTTAAAGCTGCTAATGCGCTAGA 156 R $\begin{array}{lllllllllllllllllllll}\text { F } & \text { E } & \text { T } & M & \text { P } & \text { I } & Q & \text { A } & \text { D } & \text { L } & \text { S } & \text { L } & \text { F } & \text { D } & \text { K } & \text { K } & \text { D } & \text { L } & \text { P } & \text { Y } & 87\end{array}$

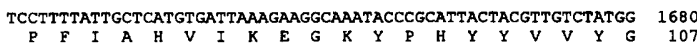
CATGAAAGGTGATCAGCTATTAATCGCTGATCCAGATAATACCGTTGGGAAGACTAAAAT 1740 GACGAAAGCGCATTTTAATGAGGAGTGGACCGGTGTGTCCATTTTTATTGCGCCAAATCC 1800 $\begin{array}{lllllllllllllllllllll}\text { T } & K & A & H & F & \text { N } & E & E & \text { W } & \text { T } & G & \text { V } & \text { S } & \text { I } & \text { E } & \text { I } & \text { A } & \text { P } & \text { N } & \text { P } & 147\end{array}$ AACCTACAAGCCAACAAAAGAAAAAAAGCGTTCCTTGACTTCTTTTATTCCCGTGATCAC 1860

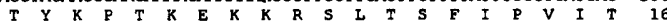
ACGACAAAAACTATTAGTTATCAATATTGTGATTGCTGCCTTATTAGTCACACTCGTTAG 1920 $\begin{array}{lllllllllllllllllllll}R & Q & K & \text { L } & \text { L } & V & \text { I } & N & \text { I } & V & \text { I } & A & A & \text { L } & \text { L } & V & T & \text { L } & \text { V } & \text { S } & 187\end{array}$ CATTTTAGGATCTTATTATTTACAAGGTATCATTGATACTTATATTCCCAATAACATGAA 1980 \begin{tabular}{lllllllllllllllllllll}
$I$ & $L$ & $G$ & $S$ & $Y$ & $Y$ & L & $Q$ & $G$ & I & I & D & T & Y & I & P & N & N & M & K & 207 \\
\hline
\end{tabular} AAACACCCTAGGAATTGTGTCACTAGGGCTTATTTTTGCGTATGTTATTCAACAATTACT 2040 $\begin{array}{lllllllllllllllllllll}N & T & \text { I } & G & \text { I } & \text { V } & \text { S } & \text { L } & G & \text { L } & \text { I } & \text { F } & \text { A } & \text { Y } & \text { V } & \text { I } & \text { Q } & Q & \text { L } & \text { L } & 227\end{array}$ ATCTTATGCTAGGGATTATTTATTAATTGTCATGGGGCAACGCCTCTCAATTGATATTAT 2100
$S$ S CTITTCTAC 2160

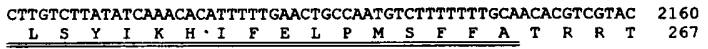
AGGTGAAATTGTGAGCCGTTTTACGGACGCTAATGCCATTATTGAAGCTCTGGCAAGCAC 2220

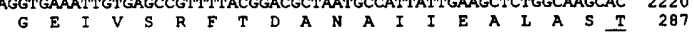
AATGTTATCAGTCTTTTTAGACTTAGGCATTTTGGTCATTGTTGGCACAGTGCTAGTGGT 2280

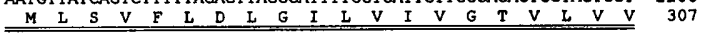
GCAAAATTCTACCTTGTTTCTTATCTCTCTGATTGCTATTCCGGCTTATGCCCTAGTTGT 2340

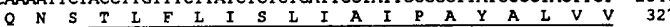

CTGGCTTTTTATGCGGCCTTTTTCCAAGATGAATAATGACCAAATGCAAGCAGGTTCGAT 2400

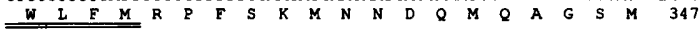
GTTGAGCTCTTCCATTATTGAAGATATTAATGGCGTTGAGACGATTAAAGCGCTGAATAG 2460 TGAAGCAACCGCCTATCATAAAATTGATCATGAATTTGTCACTTATTTAGAGAAATCATT 2520 \begin{tabular}{llllllllllllllllllll}
\hline & A T A & Y & H & K & I & D & H & E & F & V & T & Y & L & E & K & S & F & 387
\end{tabular} TGTTTACGCTAAAACAGAAGCTGTTCAAAATGCGATTAAAAGTCTCTTACAGCTCTCTTT 2580

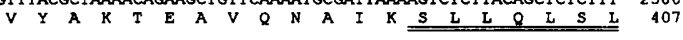

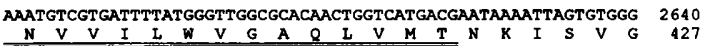
CCAACTGATCACTTACAATGCTTTATTAGGATTTTTTACAGATCCCTTGCAAAATATTAT 2700

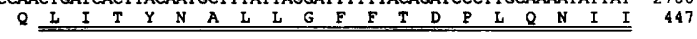

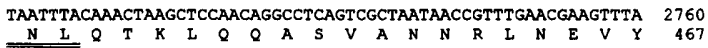
TTTGGTAGATTCAGAATTTAAAGATAGTCATCAAATGACAGAAAAAATTACGCCCAATAG 2820

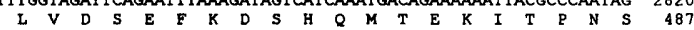
CTCACTAGTAGCCGATCATATCACCTATAAATACGGTTTTGGCGCCCCAGCGATTGATGA 2880 $\begin{array}{lllllllllllllllllllll}S & \text { L } & \text { V } & \text { A } & D & \text { H } & \text { I } & \text { T } & Y & K & \text { Y } & G & \text { F } & G & \text { A } & \text { P } & \text { A } & \text { I } & D & D & 507\end{array}$ TGTTTCACTAACGATTACAGCCGGTGAAAAAATCGCTTTGGTTGGGATTAGTGGATCAGG 2940 $\begin{array}{lllllllllllllllllllll}V & S & \text { L } & \text { T } & \text { I } & \text { T } & \text { A } & G & \text { E } & \text { K } & \text { I } & \text { A } & \text { L } & \text { V } & \text { G } & \text { I } & \mathbf{S} & \mathbf{G} & \mathbf{3} & \mathbf{G} & 527\end{array}$

GAAGTCAACTCTAGTTAAATTGCTGGTTAATTTCTTTCAACCAGAATCAGGGACTATCTC 3000

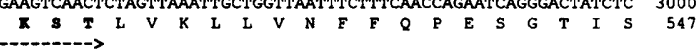
ACTGGGACCAACACCACTCGCTAATCTTGATAAACATGAGCTAAGAGGACACATTAATTA 3060 $\begin{array}{lllllllllllllllllllll}L & G & P & T & \text { P } & \text { L } & \text { A } & \text { N } & \text { L } & \text { D } & \text { K } & \text { H } & \text { E } & \text { L } & \text { R } & \text { G } & \text { H } & \text { I } & \text { N } & \text { Y } & 567\end{array}$ L P Q P F I F S G S I M E N L L L G A 3120

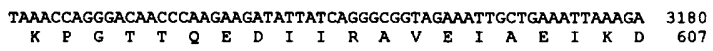
TGATATTGAAAAAATGTCACAAGGATTTGGCACTGAACTCGCCGAAAGCGGTAATATATC 3240 $\begin{array}{lllllllllllllllllllll}D & I & E & K & M & S & Q & G & F & G & T & E & L & A & E & S & G & N & \text { I } & S & 627\end{array}$

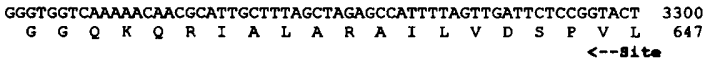
GATTTTAGATGAGTCAACCAGTAATCTTGATGTGTTAACAGAAAAAAAGATTATTGATAA 3360 $\begin{array}{lllllllllllllllllllll}I & \text { L } & D & E & \text { S } & \text { T } & \text { S } & \text { N } & \text { L } & \text { D } & \text { V } & \text { L } & \text { T } & \text { E } & \text { K } & \text { K } & \text { I } & \text { I } & \text { D } & \text { N } & 667\end{array}$ TCTCATGAAGTTAACCGAGAAAACCATTATCTTTGTAGCGCACCGCTTAACCATTTCACA 3420

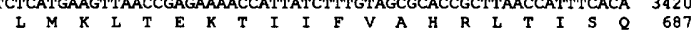

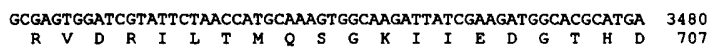

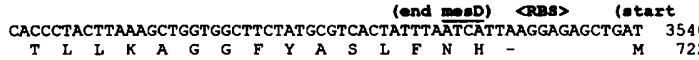

GTTT

GTTTGATCCAAAATACTTAGAAAGTGGCGAATTTTATCAACGTCGTTACCGCAATTTTCC 3600

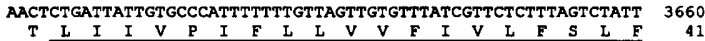
TGCTAAGCGTGAAATTGTTGTCAAAGCCAGTGGCGAAATTATTCCAGCTAAAGTGTTATC 3520 $\begin{array}{lllllllllllllllllllll}A & K & R & E & I & V & V & K & A & S & G & E & I & I & P & A & K & V & L & S & 61\end{array}$ AgATATCCAATCAACGAGTAATAATGCCATTGATAGTAACCAATTAGCCGAMAATAAAAT 3580

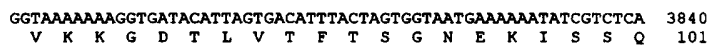
ATTATTGACGCAACAAATTAATAACCTTAACAATCGGATACAAAGTCTTGATACTTATAA 3900 $\begin{array}{lllllllllllllllllllll} & \text { I } & T & Q & Q & I & N & N & \text { L } & N & N & R & I & Q & S & \text { L } & \text { D } & T & Y & K & 121\end{array}$ GCATAGTATTATTGATGGACGAAGTGAATTTGGTGGCACAGATCAATTTGGTTATGATAA 3960 $\begin{array}{llllllllllllllllllllll}H & S & I & I & D & G & R & S & E & F & G & G & T & D & Q & F & G & Y & D & N & 141\end{array}$

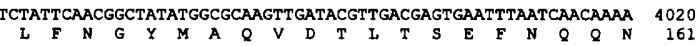
TAGTGATAAACAAACCGCTGATCAACAAGCTAATCATCAAATTGACGTTTTAAAACAAGG 4080 CCAATCTAAAAACAATCAACAATTAGCCAATTATCAAGCTATTTTAACCAGTATTAATAG 4140

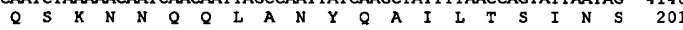
CAACACTAAACCAACTAATAATCCCTATCAGTCCATTTATGATAATTATGCAGCCCAGTT 4200 $\begin{array}{lllllllllllllllllllll}N & T & K & P & T & \text { N } & \text { N } & \text { P } & \text { Y } & Q & \text { S } & \text { I } & \text { Y } & \text { D } & \text { N } & \text { Y } & \text { A } & \text { A } & \mathbf{Q} & \text { L } & 221\end{array}$ AAAATCAGCACAAACAACTGATGATAAAGAGCAAGTCAAGCAAACTGCCTTAAGTAGTGT 4260

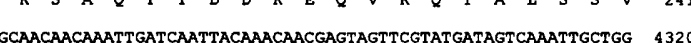

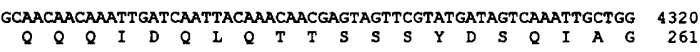
TATTACAAAAAGTGGTCCTTTATCTCAAAGCAGTACCTTAGATAAAATCGCTGACTTGAA 4380 GCAACAACAACTAGCAAGTGCTCAAAAAGAAATCAATGATCAGCAACAATCCTTAGATGA 4440 $\begin{array}{lllllllllllllllllllll}Q & Q & Q & L & A & S & A & Q & K & E & I & N & D & Q & Q & Q & S & L & D & E & 301\end{array}$ ATTAAAAGCCAAGCAATCATCTGCTAATGAGGACTATCAAGATACGGTTATTAAAGCACC 4500 $\begin{array}{lllllllllllllllllllll}I & K & A & K & Q & S & S & A & N & E & D & Y & Q & D & T & V & I & K & A & P & 321\end{array}$ AGAAAGCGGTATTCTGCATTTAACCAGTGATAAAGCAACTATAAAGTATTTCCCAAAAGG 4560 $\begin{array}{lllllllllllllllllllll}E & S & G & \text { I } & \text { L } & \text { H } & \text { L } & \text { T } & \text { S } & \text { D } & \text { K } & \text { A } & \text { T } & \text { I } & \text { K } & \text { Y } & \text { F } & \text { P } & \text { K } & \text { G } & 341\end{array}$

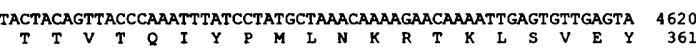
TTATGTTCCTACAAGTAATAGTGTCGGTTTAAAACGAGGACAAAACATAAGATTTGTCGC 4680 


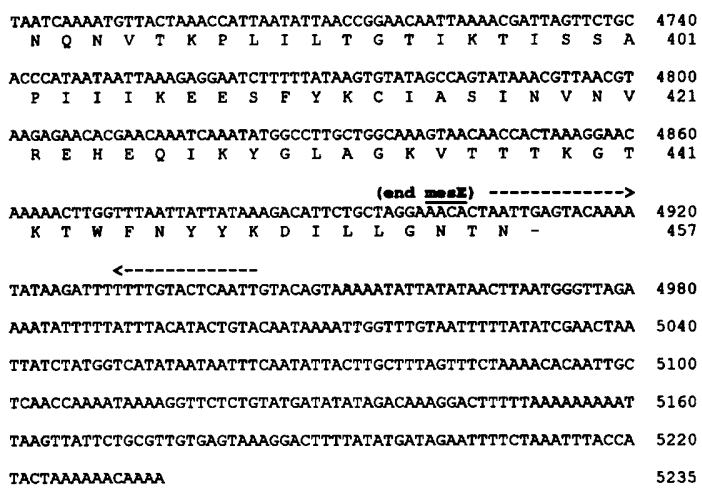

Fig. 3. Partial nucleotide sequence of the Drall fragment cloned within PCFYC2, containing the mesentericin Y105 region. ORF names are given in parentheses according to Fig. 2. Putative -10 and -35 promoter regions and putative ribosome-binding sites (RBS) are displayed. Stem-loop structures are located by facing horizontal arrows. The amino acid sequences derived from the ORFs are shown below the nucleotide sequence. The mesentericin Y105 N-terminal processing site is indicated by a vertical arrow $(\uparrow)$ within the protein sequence. The regions of the sequence noted 'Site $A$ ' and 'Site $B$ ' correspond to the $A$ and B motifs conserved within the ATP-dependent transporter family (Fath \& Kolter, 1993). Potential membrane-spanning segments in MesD and MesE are double-underlined.

Table 2. Levels of mesentericin $Y 105$ production exhibited by derivatives of $L b$. johnsonii NCK64 and NCK65

\begin{tabular}{|lcc|}
\hline Strain & $\begin{array}{c}\text { Relevant plasmid } \\
\text { characteristics }\end{array}$ & $\begin{array}{c}\text { Mesentericin Y105 } \\
\text { activity (AU ml } \mathbf{~ m}^{-1} \text { ) }\end{array}$ \\
\hline $\begin{array}{l}\text { Ln. mesenteroides } \\
\text { Y105 }\end{array}$ & $\mathrm{pHY} 30$ & 12800 \\
Lb. johnsonii & & \\
CFYC6 & Erm $^{\mathrm{R}}$ & $<100^{*}$ \\
CFYC7 & Erm $^{\mathrm{R}}$ & $<100^{*}$ \\
CFYC8 & Erm $^{\mathrm{R}}$, mes $Y$, mesI & $100-3200 \dagger$ \\
CFYC9 & Erm $^{\mathrm{R}}$, mes $Y$, mesI & $100-400 \dagger$ \\
\hline
\end{tabular}

* Bactericidal activity, if any, was below the threshold of detection. † Level of mesentericin Y105 production was variable depending on the transformant analysed.

1992), respectively. Hydrophobicity analysis of the deduced MesE predicted a mostly hydrophilic protein with the exception of the region from residues 20 to 42 . Within this region, computer analysis (Klein et al., 1985) indicates a putative $\alpha$-helix (residues 22 to 42 , Fig. 3 ). It contains only hydrophobic residues surrounded by positively charged amino acids, and therefore may be a transmembrane anchor. Sequence alignments (not shown) displayed similarities $(35.2 \%$ identity and $17.5 \%$ similarity) between MesE and the putative accessory factor LcnD which is required for lactococcin secretion (Stoddard et al., 1992), thus, suggesting a possible role for
MesE in the mesentericin Y105 secretion process. Comparison of the predicted protein sequence $\mathrm{Mes} C$ with protein sequences of data bases did not show any significant similarity.

\section{DISCUSSION}

As reported previously, Ln. mesenteroides Y105 produces a small heat-labile bacteriocin (class II, according to Klaenhammer, 1993), designated mesentericin Y105, which is active against various Listeria species (Héchard $e t$ al., 1992a). We have located the mesentericin Y105 genetic determinants on plasmid pHY30 and described a DNA region from this plasmid that is involved in the production of the mesentericin Y105. A $8 \mathrm{~kb}$ DraII fragment from pHY30 has been cloned that contains the mesentericin Y105 structural gene, mes $Y$. Sequence analysis of $5235 \mathrm{bp}$ of the cloned fragment revealed, in addition to mes $Y$, the presence of four complete ORFs organized in two gene clusters. One cluster includes mes $Y$ and mesI, the putative gene encoding immunity to mesentericin Y105, and is preceded by a putative promoter and followed by a stem-loop structure that may act as a terminator. Thus, $m e s Y$ and $m e s I$ are likely to form an operon. Likewise, $m e s C, m e s D$ and mesE may form a second operon-like structure that is transcribed in the opposite direction with a promoter region overlapping the promoter region of the mes $Y$-mesI operon. Messenger RNA analyses are underway to verify this hypothesis. To date, this genetic organization seems unique for bacteriocin operons from lactic acid bacteria; indeed, equivalent genes in other bacteriocin systems such as lactococcin $A$ and $M$ (Stoddard et al., 1992; van Belkum, 1994) and pediocin PA-1 (Marugg et al., 1992) are all located onto the same DNA strand.

Comparison between the amino acid sequence deduced from the gene with that of the purified bacteriocin (Héchard et al., 1992a) indicates that mesentericin Y105 is first translated as a 61 amino acid precursor, then posttranslationally processed by cleavage of a 24 residue $\mathrm{N}$ terminal extension at a specific site (val-val-gly-gly $\downarrow$ Lys). This specific cleavage site is believed to be common to all class II bacteriocins (Håvarstein et al., 1994), and indeed, analysis of the mesentericin Y105 propeptide points out some of the striking similarities common to all the class II bacteriocin propeptides (Fremaux et al., 1993). Gene sequence determination confirmed the amino acid sequence of mesentericin Y105 obtained from the purified peptide except for an additional tryptophan in the terminal position. Therefore, in spite of minor differences in the amino acid sequence, this bacteriocin is believed to be truly different from the leucocin A, because of their different activity spectra and their mode of action (bactericidal versus bacteriostatic). In addition, comparison of the DNA sequence over $1088 \mathrm{bp}$ between leucocin A and mesentericin Y105 genetic loci showed numerous differences, mostly located at the wobble position in the coding regions (not shown). This probably reflects a divergent genetic evolution of a common ancestor 
plasmid that underwent mutagenesis and rearrangement, the latter explaining the low similarity level observed within the regions downstream of the operon.

For many bacteriocin systems in lactic acid bacteria, an immunity gene has been characterized and located downstream of the bacteriocin structural gene (van Belkum $e t$ al., 1991a, 1992; Marugg et al., 1992). Located directly downstream of the bacteriocin structural gene, mesI encodes a protein of 113 amino acids. Therefore, mesI represents a good candidate for the immunity determinant.

A protein homology search revealed important similarities (from 66 to $76 \%$ ) between LcnC, PedD and ComA and the protein deduced from mesD. LcnC and PedD proved to be required for the production of lactococcin $A$ (Stoddard et al., 1992) and pediocin PA-1 (Marugg et al., 1992), respectively. ComA is one of the proteins required to facilitate genetic transformation of $S$. pneumoniae (Hui \& Morrison, 1991). Phylogenetic analysis indicates that these four proteins formed one branch of a large phylogenetic tree grouping the ATP-dependent transporters (Fath \& Kolter, 1993). Globally, these data suggest that MesD participates in mesentericin Y105 exportation, and indeed, as for all the ATP-dependent transporters, the central region of MesD presents a membrane-spanning domain containing several putative trans-membrane-helices, and the C-terminal region contains the highly conserved ATP-binding domain. Many of the dedicated bacterial exporters require additional proteins beside the transporter itself to form a functional complex. One protein is referred to as the accessory factor, where its structural gene is usually linked to the ATP-dependent transporter gene within an operon (Fath \& Kolter, 1993). In particular, LcnD and ComB are required for the production of lactococcin $\mathrm{A}$ and the competence factor from $S$. pneumoniae, respectively, and they share sequence similarity with the accessory factor from Gram-negative bacteria. The gene mes $D$, encoding the putative transporter of mesentericin Y105, is genetically associated with two other genes in an operon (mes $C$ and mesE), from which mesE encodes a protein having $52.7 \%$ similarity to $\mathrm{LcnD}$, thus suggesting a possible role in bacteriocin secretion.

To analyse the mesentericin Y105 operon, shuttleplasmid pCFYC5 containing mes $Y$ and mesI was constructed. Unfortunately, none of the attempted electroporation protocols yielded any transformant of $L n$. mesenteroides $\mathrm{Y} 30$. Consequently, trials to express the cloned structural gene of mesentericin Y105 were done in a heterologous host that does not express any anti-Listeria activity. Lb. jobnsonii NCK64, a non-producing derivative of the natural lactacin F producer (see Table 1) with a frameshift mutation in the lactacin F structural gene, was chosen. Bactericidal activity against Listeria was obtained with NCK64 clones containing pCFYC5, suggesting that NCK64 contains the whole machinery required for the production of the mesentericin Y105. It is possible that the lactacin $\mathrm{F}$ maturation and secretion functions can support heterologous expression of mesentericin Y105.
However, the lower level of bacteriocin, compared to the parental mesentericin Y105 producer, likely reflects decreased affinity of these functions for mesentericin Y105. Another explanation lies in an insufficient expression level of these chromosomally encoded functions for the expression of the bacteriocin gene located on the multi-copy plasmid pCFYC5. Heterologous bacteriocin production has also been obtained for lactacin $\mathrm{F}$ in $\mathrm{Ln}$. gelidum UAL187, which naturally produces leucocin A (Klaenhammer et al., 1994). Therefore, these overall data, in addition to protein sequence similarities and common processing sites, provide strong evidence for the operation of homologous processing and export systems for the production of the class II bacteriocins from lactic acid bacteria. This peculiar feature may be of great interest for future development of engineered strains for industrial fermentations that produce various bacteriocins that are active against a broad spectrum of pathogens.

\section{ACKNOWLEDGEMENTS}

This work has been achieved as a part of the program 'BIOAVENIR' (contract \# 780227) supported by RhônePoulenc with the participation of the Ministère de la Recherche et de l'Espace and the Ministère de l'Industrie et du Commerce Extérieur. We thank Todd R. Klaenhammer, Department of Food Science, North Carolina State University, USA, for providing $L b$. johnsonii strains. We are also grateful for the gift of pGKV210 from Jan Kok, Department of Genetics, University of Groningen, The Netherlands.

\section{REFERENCES}

Abee, T., Klaenhammer, T. R. \& Letellier, L. (1994). Kinetic studies of the action of lactacin $\mathrm{F}$, a bacteriocin produced by Lactobacillus jobnsonii that forms poration complexes in the cytoplasmic membrane. Appl Environ Microbiol 60, 1006-1013.

Allison, G. E., Fremaux, C. \& Klaenhammer, T. R. (1994). Expansion of bacteriocin activity and host range upon complementation of two peptides encoded within the lactacin $\mathrm{F}$ operon. $J$ Bacteriol 176, 2235-2241.

Barefoot, S. F. \& Klaenhammer, T. R. (1983). Detection and activity of lactacin B, a bacteriocin produced by Lactobacillus acidophilus. Appl Environ Microbiol 45, 1808-1815.

van Belkum, M. J. (1994). Lactococcins, bacteriocins from Lactococcus lactis. In Bacteriocins of Lactic Acid Bacteria, pp. 301-318. Edited by L. De Vuyst \& E. J. Vandamme. London: Chapman \& Hall.

van Belkum, M. J., Hayema, B. J., Jeeninga, R. J., Kok, J. \& Venema, G. (1991a). Organization and nucleotide sequences of two lactococcal bacteriocin operons. Appl Environ Microbiol 57, 492-498.

van Belkum, M. J., Kok, J., Venema, G., Holo, H., Nes, I. F., Konings, W. N. \& Abee, T. (1991b). The bacteriocin lactococcin A specifically increased the permeability of lactococcal cytoplasmic membrane in a voltage-independent, protein-mediated manner. $J$ Bacteriol 173, 7934-7941.

van Belkum, M. J., Kok, J. \& Venema, G. (1992). Cloning, sequencing, and expression in Escherichia coli of $\ln B$, a third bacteriocin determinant from the lactococcal plasmid p9B4-6. Appl Environ Microbiol 58, 572-577.

Chikindas, M. L., Garcia-Garcera, M. J., Driessen, A. J. M., Ledeboer, A. M., Nissen Meyer, J., Nes, I. F., Abee, T., Konings, W. 
N. \& Venema, G. (1993). Pediocin PA-1, a bacteriocin from Pediococcus acidilactici PAC1.0, forms hydrophilic pores in the cytoplasmic membranes of target cells. Appl Environ Microbiol 59, 3577-3584.

De Vuyst, L. \& Vandamme, E. J. (1994). Antimicrobial potential of lactic acid bacteria. In Bacteriocins of Lactic Acid Bacteria, pp. 91-142. Edited by L. De Vuyst \& E. J. Vandamme. London: Chapman \& Hall.

Fath, M. J. \& Kolter, R. (1993). ABC transporters: bacterial exporters. Microbiol Rev 57, 995-1017.

Fath, M. J., Skvirsky, R., Gilson, L., Mahanty, H. K. \& Kolter, R. (1992). The secretion of colicin V. In Bacteriocins, Microcins, and Lantibiotics, pp. 331-348. Edited by R. James, C. Ladzunsky \& F. Pattus. Heidelberg: Springer-Verlag.

Fremaux, C., Ahn, C. \& Klaenhammer, T. R. (1993). Molecular analysis of the lactacin F operon. Appl Environ Microbiol 59, 3906-3915.

Hanahan, D. (1983). Studies on transformation of Eschericbia coli with plasmid DNA. J Mol Biol 166, 557-580.

Hastings, J. W., Sailer, M., Johnson, K., Roy, K. L., Vederas, J. C. \& Stiles, M. E. (1991). Characterization of leucocin A-UAL 187 and cloning of the bacteriocin gene from Leuconostoc gelidum. J Bacteriol 173, 7491-7500.

Håvarstein, L. S., Holo, H. \& Nes I. F. (1994). The leader peptide of colicin $\mathrm{V}$ shares consensus sequences with leader peptides that are common among peptide bacteriocins produced by Gram-positive bacteria. Microbiology 140, 2383-2389.

Héchard, Y., Dérijard, B., Letellier, F. \& Cenatiempo, Y. (1992a). Characterization and purification of mesentericin Y105, an antiListeria bacteriocin from Leuconostoc mesenteroides. J Gen Microbiol 138, 2725-2731.

Héchard, Y., Jayat, C., Letellier, F., Julien, R., Cenatiempo, Y. \& Ratinaud, M. H. (1992b). On-line visualization of the competitive behavior of antagonistic bacteria. Appl Environ Microbiol 58, 3784-3786.

Holk, A., Axelsson, L., Birkeland, S.-E., Aukrust, T. \& Blom, H. (1992). Purification and amino acid sequence of sakacin $A$, a bacteriocin from Lactobacillus sake Lb706. J Gen Microbiol 138, 2715-2720.

Holo, H., Nilsen, O. \& Nes, I. F. (1991). Lactococcin A, a new bacteriocin from Lactococcus lactis subsp. cremoris: isolation and characterization of the protein and its gene. $J$ Bacteriol 173, 3879-3887.

Hui, F. M. \& Morrison, D. A. (1991). Genetic transformation in Streptococcus pneumoniae: nucleotide sequence shows $\operatorname{com} A$, a gene required for competence induction, to be a member of the bacterial ATP-dependent transport protein family. J Bacteriol 173, 372-381.

Klaenhammer, T. R. (1993). Genetics of bacteriocins produced by lactic acid bacteria. FEMS Microbiol Rev 12, 39-85.

Klaenhammer, T. R., Ahn, C. \& Muriana, P. M. (1994). Lactacin F, a small hydrophobic heat-stable bacteriocin from Lactobacillus jobnsonii. In Bacteriocins of Lactic Acid Bacteria, pp. 377-396. Edited by L. De Vuyst \& E. J. Vandamme. London: Chapman \& Hall.

Klein, P., Kanehisa, M. \& DeLisi, C. (1985). The detection and classification of membrane-spanning proteins. Biochim Biophys Acta 815, 468-476.
Koivula, T., Sibakov, M. \& Palva, I. (1991). Isolation and characterization of Lactococcus lactis subsp. lactis promoters. Appl Environ Microbiol 57, 333-340.

Kozak, M. (1983). Comparison of initiation of protein synthesis in procaryotes, eucaryotes and organelles. Microbiol Rev 47, 1-45.

Maftah, A., Renault, D., Vignoles, C., Héchard, Y, Bressolier, P., Ratinaud, M. H., Cenatiempo, Y. \& Julien, R. (1993). Membrane permeabilization of Listeria monocytogenes and mitochondria by the bacteriocin mesentericin Y105. J Bacteriol 175, 3232-3235.

Marugg, J. D., Gonzalez, C. F., Kunka, B. S., Ledeboer, A. M., Pucci, M. J., Toonen, M. Y., Walker, S. A., Zoetmulder, L. C. M. \& Vandenbergh, P. A. (1992). Cloning, expression, and nucleotide sequence of genes involved in production of pediocin PA-1, a bacteriocin from Pediococcus acidilactici PAC1.0. Appl Environ Microbiol 58, 2360-2367.

Mayr-Harting, A., Hedges, A. J. \& Berkeley, R. C. W. (1972). Methods for studying bacteriocins. Methods Microbiol 7A, 315-422.

Muriana, P. M. \& Klaenhammer, T. R. (1987). Conjugal transfer of plasmid-encoded determinants for bacteriocin production and immunity in Lactobacillus acidophilus 88. Appl Environ Microbiol 53, 553-560.

Muriana, P. M. \& Klaenhammer, T. R. (1991). Cloning, phenotypic expression, and DNA sequence of the gene for lactacin $F$, an antimicrobial peptide produced by Lactobacillus spp. J Bacteriol 173, 1779-1788.

Nieto Lozano, J. C., Nissen Meyer, J., Sletten, K., Peláz, C. \& Nes, I. F. (1992). Purification and amino acid sequence of a bacteriocin produced by Pediococcus acidilactici. J Gen Microbiol 138, 1985-1990.

Raya, R. R., Fremaux, C., De Antoni, G. L. \& Klaenhammer, T. R. (1992). Site-specific integration of the temperate bacteriophage Фadh into the Lactobacillus gasseri chromosome and molecular characterization of the phage (attP) and bacterial (attB) attachment site. J Bacteriol 174, 5584-5592.

Sambrook, J., Fritsch, E. F. \& Maniatis, T. (1989). Molecular Cloning: a Laboratory Manual, 2nd edn. Cold Spring Harbor, NY: Cold Spring Harbor Laboratory.

Sanger, F., Nicklen, S. \& Coulson, A. R. (1977). DNA sequencing with chain-terminating inhibitors. Proc Natl Acad Sci US A 74, 5463-5467.

Stoddard, G. W., Petzel, J. P., van Belkum, M. J., Kok, J. \& McKay, L. L. (1992). Molecular analysis of the lactococcin A gene cluster from Lactococcus lactis subsp. lactis biovar. diacetilactis WM4. Appl Environ Microbiol 58, 1952-1961.

Southern, E. M. (1975). Detection of specific sequences among DNA fragments separated by gel electrophoresis. $J$ Mol Biol 98, 503-517.

Tagg, J. R., Dajani, A. S. \& Wannamaker L. W. (1976). Bacteriocins of Gram-positive bacteria. Bacteriol Rev 40, 722-756.

Venema, K. T., Abee, T., Haandrikman, A. J., Leenhouts, K. J., Kok, J., Konings, W. N. \& Venema, G. (1993). Mode of action of lactococcin B, a thiol-activated bacteriocin from Lactococcus lactis. Appl Environ Microbiol 59, 1041-1048.

van der Vossen, J. M. B. M., van der Lelie, D. \& Venema, G. (1987). Isolation and characterization of Streptococcus cremoris Wg2specific promoters. Appl Environ Microbiol 53, 2452-2457.

Received 25 November 1994; revised 23 February 1995; accepted 21 March 1995. 